\title{
ESCLARECIMENTOS E ESTÉTICA NUMA SÉRIE DE PARADOXOS
}

KAPP, Silke. Non Satis Est: Excessos e Teorias Estéticas no Esclarecimento. Porto Alegre: escritos, 2004, 357 p.

\author{
Arthur Grupillo* \\ in1954@hotmail.com
}

Nos passeios da feira de domingo, não raro surpreendo-me seduzido por uma vontade irresistível de permanecer olhando uma pessoa. E, às vezes, isso acontece por ver nela tanta feiúra reunida. Não é melhor que ver, e permanecer sorrateiramente vendo, uma bela pessoa. Mas, sem dúvida, é melhor que passar de um rosto transeunte a outro, enquanto esbarram na gente, a constatar que todos são entediantemente normais. Partindo de uma evidência simples como essa, a obra de Silke Kapp empreende uma pesquisa histórica e exegética fecunda, com forte vigor teórico e filosófico de pano de fundo, e propõe uma compreensão fascinante da própria experiência estética. Tudo isso manifesto por uma redação limpa e clara, erudita sem dúvida, e que, acima de tudo, sabe transitar do vocabulário acadêmico à livre reflexão. Bibliografia básica para o esteta de língua portuguesa, que terá nas mãos também um levantamento acurado da literatura secundária sobre as estéticas dos séculos XVII e XVIII. As chamadas estéticas do esclarecimento são rigorosamente estudadas para que nelas se evidencie o paradoxo do excesso, definido como o que vai além do satisfatório, "podendo, por isso, incrementar a satisfação tanto quanto revertê-la" (p. 24). Distorções, dissonâncias, assimetrias, desordens e desproporções, quando provocam, caracterizam muito mais a experiência estética do que a consonância, a simetria, a ordem e a proporção que não

* Mestre em filosofia pela Universidade Federal de Minas Gerais.

KRITERION, Belo Horizonte, nº 113, Jun/2006, p. 191-198. 
conseguem encantar. Ao enfrentar essa questão, o esclarecimento se depara com seus limites. A dialética que se cristaliza na sede esclarecida de dominar conceitualmente tais excessos é o que se procura mostrar com a pesquisa histórico-exegética. Uma dialética do esclarecimento estético se mostra, enquanto se projeta, no desenvolvimento da trama, uma caracterização da própria experiência estética como aquilo que excede e, portanto, escapa.

O livro está dividido em quatro capítulos organizados de modo a permitir ao leitor manter o fio condutor da argumentação. Uma Introdução sem título, antes, faz as vezes de porta-voz do trabalho e expõe sucintamente o vínculo entre as estéticas do esclarecimento e o próprio nascimento da estética filosófica. Kapp trabalha diferentes aspectos do contexto filosófico iluminista e tenta apontar nele uma ambigüidade fundamental: a necessidade de enfrentamento teórico do irracional e do singular a partir das novas premissas da moderna filosofia. E, uma vez que a experiência estética aparece como a "herdeira" dos conteúdos mágicos renegados pelo esclarecimento, o irracional estético passa a primeiro plano, e a dialética do esclarecimento mostra ali seus primeiros sinais. A gênese da idéia de que um modo de ver o mundo esteticamente alivia os sujeitos da pressão cognitiva e moral, abrindo precedente para aqueles conteúdos reprimidos serem revisitados sem incompatibilizar o homem com a racionalidade nascitura, é encontrada na história das idéias estéticas a respeito do excesso, do que extrapola o racional, e essa coincide com a história da emancipação da esfera estética na modernidade. Isso, porque, se algo está de acordo com as regras do conhecimento teórico, não necessariamente apraz. E freqüentemente encontramos em nós um prazer secreto pelo doloroso e o medonho. $\mathrm{O}$ que não falar então do estranho gosto por catástrofes e tragédias? Enfim, quando as estéticas esclarecidas descobrem que a prescrição de regras não garante o fim último da obra, agradar, e que o prazer reside, muitas vezes, na transgressão do normal, do natural e do conveniente, faz sentido falar de um domínio estético, não completamente redutível a premissas lógicas, epistemológicas ou morais.

O primeiro capítulo visa mostrar a efetividade de um gosto humano por excessos e como esse gosto manifesta uma relação com um mundo encantado rejeitado pela razão científica. O período artístico em questão é perturbado pela famosa querelle des anciens et des modernes, no plano prático e no teórico. Os últimos suspiros do classicismo já não encontram realidade numa época em que a individuação vai prevalecendo sobre a idealidade e, por isso, já não pode abrir mão de desvios e feiúras, que constituem a diferença do individual em relação ao modelo. Também a natureza não escapa a essa disposição. A partir do relato de John Dennis de sua viagem aos Alpes, Kapp 
chama atenção para o modo como esse novo olhar artístico reencanta a natureza. Admirada apenas por sua legalidade e harmonia na visão do olhar esclarecido, a natureza também pode encantar por sua grandeza e desmesura, pelo pavor que promete com suas forças violentas. A natureza indomável permeada de personagens amedrontadores, que já não fazia sentido para a ciência, converte-se num repositório infinito de idéias estéticas. Mas tudo só fica fora de dúvidas diante da verve dialética da autora. A dominação técnica da natureza só efetivou-se mesmo no século XIX. O que torna possível este prazer sublime descrito por Dennis diante dos abismos dos montes alpinos, segundo Kapp, é a convivência de um desencantamento teórico do mundo e sua promessa ainda não cumprida (será um dia?) de uma absoluta dominação técnica da natureza. "Sabe-se que os motivos desse temor são irreais; por outro lado, tais motivos ainda estão próximos o suficiente para que os sentimentos por eles suscitados não tenham sido esquecidos." (p. 61). Mesmo as interferências estéticas no entorno natural explicam-se mais por uma visão ideológica da natureza do que pela disponibilidade de recursos técnicos, como é o caso do chamado "jardim francês", paradigma do desenho paisagístico do século XVII.

Sem tratores nem serra elétrica, Versailles é devastada pela topiaria e seu ímpeto nivelador, geometrizando violentamente a paisagem sem qualquer respeito por suas curvas. De outro lado, o "jardim inglês" constrói artificialmente uma natureza selvagem idealizada. A tentativa de interiorização e superação desse momento do particular e do excesso nas regras do ajardinamento inglês é denunciada por Kapp como uma falsa reconciliação, com o que se pretende preservar o momento negativo dessa dialética, mais patente nas gravuras de Piranesi. Contra a falsa pacificação idealizadora, uma objetividade abissal. Nas gravuras dos Carceri, Piranesi mantém a mais calculada estrutura arquitetônica, que se revela, afinal, insuficiente e frustrante na apreensão do todo. Pilares e escadas se harmonizam matematicamente para sustentar nada e levar a lugar nenhum. "Essa demonstração do arruinamento de toda regra arquitetônica ou mesmo física torna as gravuras mais assustadoras do que o faria o uso de ingredientes grotescos e mórbidos." (p. 85). Por tudo isso, Kapp considera correto falar de uma aceleração da dialética do esclarecimento na esfera estética. Essa dialética ainda é o espírito que move as pesquisas da autora nos capítulos subseqüentes, destinadas a caçar nas obras dos estetas esclarecidos o ponto cego onde o excesso se esconde e resiste à caracterização conceitual.

O segundo capítulo, "O Tédio e o Sublime", trata de Nicolas Boileau-Despréaux (1636-1711), e a investigação é levada a cabo como um contraponto entre as suas duas principais obras. Kapp encontra múltiplas 
contradições e aporias insolúveis em Art Poétique, obra de um Boileau racionalista e prescritivo, que seriam sintomas de teses defendidas na segunda obra, o Traité du Sublime. O excesso que valia apenas para certos gêneros literários, o que já representa uma incongruência do primeiro Boileau, vale agora para a poesia em geral. Há um aprendizado técnico que ainda se considera necessário, mas que nada pode se não houver um "gênio" que transforme tal domínio em excelência estética. O prazer estético passa a ser definido como oposto ao tédio, não como oposto ao mal ou à falsidade. Uma obra pode seguir todas as regras prescritas e ser entendiante e é perfeitamente possível que algo aprazível na percepção seja estranho à razão. Nascemos para o extraordinário!

O terceiro capítulo, "Os Prazeres da Imaginação", cuida de John Dennis (1657-1734), Joseph Addison (1672-1719), e o abade Jean Baptiste Dubos (1670-1742). De todos os autores trabalhados, Dennis é o que mais evidencia a relação entre a nova experiência estética e o mundo encantado da transcendência mística, ignorado pela ciência. O importante para Dennis é o "entusiasmo", uma interação muito singular entre sensibilidade, imaginação e razão, um sentimento que nem todos têm e casa perfeitamente com o tratamento estético dado às idéias religiosas (p. 173).

Addison representa um passo além de Dennis e Boileau, porque não parte dos problemas relativos à própria poesia, mas ao sujeito e suas atividades mentais. O conceito de imaginação é desenvolvido quando Addison lê os problemas estéticos à luz da subjetividade lockeana, empreendimento promissor, mas ambíguo desde o início. Amplia-se a atividade da imaginação na consecução do conhecimento, ao mesmo tempo em que se lhe cerceia a influência. "Sentimento e imaginação adquirem um caráter ameaçador, porque as suas quimeras são, por assim dizer, feitas do mesmo material da verdade: delírio e verdade são ambos representações do sujeito.” (p. 184). Mas os fenômenos estéticos enfrentados por Addison forçaram as portas da trama conceitual da filosofia do sujeito, levando-o a propor uma das idéias mais esclarecedoras quanto à caracterização da forma subjetiva moderna de ver o mundo. A imaginação toma o lugar antes ocupado pela noção de mímesis e passa a ser responsável por um modo mais flexível de ver as coisas, mediado pela livre associação de idéias. "Na sua concepção, a natureza é vista pelo "homem sábio" tanto à luz da imaginação quanto à luz do entendimento, sem que esses modos de vê-la se perturbem mutuamente." (p.193) À luz da nova filosofia do sujeito, uma verdadeira psicologia do tédio é tematizada, sobretudo com Dubos, e consolida-se uma caracterização da experiência estética como uma autoconsciência das próprias forças mentais. Contra o tédio, propõe-se uma definição do prazer como uma experiência da atividade da 
alma, mesmo diante de uma representação que contraria avaliações cognitivas e morais. O tédio é, nesses autores, interpretado como um efeito do desencantamento, e a ele se responde com um reencantamento estético, um modo de ver o mundo pela imaginação, onde o particular e o desvio são preservados. Kapp domina a arte da pesquisa textual, e consegue encontrar nas repetitivas palavras de seus autores detalhes exegéticos instigantes, como sobre a questão da "segurança" do próprio sujeito na experiência do excesso; mas a chave de leitura para a compreensão dos objetivos de Kapp quanto a esses autores é a seguinte insuspeitada passagem: "Se o sublime de Boileau, o entusiasmo de Dennis, a imaginação de Addison e o gosto de Dubos são capazes de abrigar teoricamente algo desses excessos é por não se tratar de conceitos que esses autores julguem passíveis de universalização. Eles são conceitos destinados - para usar a expressão de Adorno - a algo de 'não-idêntido'." (p. 213-214).

É preciso considerar que Non Satis Est é resultado da pesquisa de doutoramento da autora, cuja trajetória intelectual inclui incursões adornianas. O leitor que desconsiderar essa psicologia do texto perderá de vista a tese doutrinal que Kapp pretende com tanto trabalho histórico e exegético. O livro em questão circunscreve um capítulo da dialética do esclarecimento. Kapp sabe que enfrentar a questão que ela se coloca: como a dissensão entre juízos estéticos e juízos conceituais é refletida filosoficamente? "está atada às premissas teóricas do esclarecimento" (p. 275). Esse é um dos motivos pelo qual a autora precisa rejeitar uma interpretação da existência desses conteúdos não conceituais como simples exemplo de um emocionalismo ou sensualismo, tal como nas estéticas de Burke e Hume, que concordariam com as premissas de Kapp sem onerar esse excesso como um outro que escapa à razão. $\mathrm{O}$ conceito de excesso defendido tem menos do naturalismo fisiocrata dos empiristas do que do naturalismo especulativo de Frankfurt (do marxismo e da psicanálise). A forma como Kapp resolve esse problema não está óbvia no texto, mas parece depender da instauração do que ela chama de sensações mistas, assunto do capítulo IV, “As Fronteiras do Belo".

Nesse capítulo, Kapp lança mão de seu espírito dialético a fim de retomar uma discussão sobre o poder político-pedagógico da arte desde Platão, e tenta resolver as insuficiências de Burke juntamente com Mendelssohn e seu modelo conceitual adequado às sensações mistas. Desta vez, o excesso é definido em relação ao esclarecimento prático, como aquilo que transgride os próprios sentimentos morais, tão preciosos às filosofias do moral sense, que remontam a Shafesbury e da qual Burke é um dos representantes.

A autora denuncia a estratégia da utilização político-pedagógica da arte pelo poder. Ao mesmo tempo em que demoniza a poesia, Platão a considera 
adequada se o objetivo é formar a parte não racional da alma nas massas. Nesse contexto, a autora defende uma tese de conseqüências devastadoras: "A doutrina platônica das fábulas educativas pode ser interpretada como o início de uma "vinculação automatizada entre a arte e a beleza" que, ao longo de mais de dois mil anos, teve por propósito "controlar e censurar a representação da violência" nas artes, para ocultar a "carranca" do próprio poder." (p. 221) É o espírito político que anima a verve dialética de Kapp. Essa combinação de dialética e política, ajustada a uma psicologia profunda do poder, não pode deixar de resultar num enérgico instrumento de crítica da razão, incluindo a razão estética.

Kapp consegue inventariar argumentos dessa natureza num lugar privilegiado da relação conflituosa entre arte e política, a saber, a teoria da tragédia. $\mathrm{O}$ efeito político da tragédia reside na encenação do sofrimento alheio. Nas estéticas estudadas no livro, é unânime o pressuposto de que o terror trágico é um efeito repulsivo e precisa ser compensado por uma outra paixão positiva. Burke, no entanto, permanece sólido no seu empirismo. Apesar de considerar a sociedade unida por sentimentos sociais, e não apenas por constrangimentos naturais, ele não dá nenhuma importância à poesia na formação de tais sentimentos, justamente porque vê a experiência estética estritamente de um ponto de vista fisiológico. Kapp pretende definir o excesso estético como um outro da razão, mas Burke e Hume parecem resistir, no tratamento que lhes dá a autora, a essa definição. Mas a estranha incompatibilidade de sentimentos que somos capazes de experimentar simultaneamente, seja na tragédia encenada ou na real, exige um modelo teórico que Burke não pode oferecer, justamente por não conter a dialética do esclarecimento de que Kapp precisa. O paradoxo do trágico só pode ser completamente evidenciado como um paradoxo do excesso!

Experimentamos o excesso em geral, incluindo o repulsivo moralmente, porque não nos deixamos tragar por ele; oscilamos entre a representação e o prazer que sentimos em relação ao nosso próprio ânimo em atividade diante dela. Mesmo que a percepção seja vivida como dor, a consciência da atividade da alma não pode ser recebida senão com prazer. Somente esse modelo explica a espantosa incompatibilidade de valores expressa nesse arroubo de Euphranor contra Teokles: "Tu terias te regozijado menos se o perigo não tivesse sido apresentado no mais alto grau!” (p. 261). Mas, se aceitas essas premissas, toda representação é prazerosa. Não há nenhuma dor pura que não seja recebida com prazer. Mendelssohn abre a mente para a solução ao problema quando antevê em Lessing a teoria das sensações mistas. Isto lhe permite, a um só tempo, rejeitar o empirismo de Burke e a conclusão contra-intuitiva 
a que a monadologia estética levava. Há uma representação que em geral é limite para que possamos experimentá-la como um prazer da atividade: o asco (Eckel). É o exato oposto do tédio. Enquanto o último não desperta o ânimo, o primeiro o assalta sem possibilidade de retorno à consciência e a um modo racional de ver o objeto. "Ora, se a própria experiência estética é uma experiência de excessos, que contém ultrapassagens daquilo que é tido por normal e retornos a ele, então haveria fundamentalmente dois limites que a definem: a impossibilidade da ultrapassagem ou a impossibilidade do retorno." (p. 273).

A experiência estética é demarcada então na terra-de-ninguém onde se desdobra a dialética negativa entre a consciência de si do tédio e o abandono de si do asco, e nesse espaço pode-se ir do mais regrado (belo) ao mais temível (sublime), embora a instância que caracteriza o abandono de si, na disposição à imitação e à imaginação, inclua essa relação ao outro, esse excesso (que antes caía fora da definição clássica do belo), que Kapp quer preservar e que sustenta a interpretação da experiência estética como sendo sempre uma experiência mista: uma ativa e outra passiva.

Duas questões se colocam, sobretudo porque afirmei que a pesquisa histórico-exegética tem uma finalidade doutrinal profunda. A primeira já mencionada, da possibilidade de uma explicação naturalista vulgar dessa instância não-conceitual, capaz de ser sustentada por um Burke ou um Hume. A segunda diz respeito à idéia de uma disposição à imitação ou a ver o mundo com os olhos da imaginação. Kapp confia demasiado na unanimidade dos estetas do esclarecimento quanto à caracterização desse modo não-conceitual de ver o mundo como sendo imediato: "O gosto aprova ou rechaça imediatamente, e isso o distingue do chamado 'raciocínio'.” (p. 276). Existem autores, como Kant, que entendem o gosto como mediado pela reflexão. O importante é que, de um modo geral, podemos caracterizar tal disposição como a instauração de uma mediação racional. O modelo que Kapp constrói com Mendelssohn contém a idéia de que a fusão visceral com o objeto, que é limite da experiência estética, depende da "proximidade do objeto da representação a nós mesmos - no extremo, ao nosso corpo", o que depende, por sua vez, daquilo "que o sujeito considera uma parte de si” (p. 271). Ao mesmo tempo, numa passagem importante para Kapp, Mendelssohn aponta claramente a incapacidade de certas pessoas em transitar de um modo de ver o mundo a outro: "Vimos que é necessária uma certa habilidade para se entregar à ilusão e em prol dela, abrir mão da consciência do presente durante o tempo em que ela oferece deleite; e, no entanto, assim que ela começa a se tornar desagradável, chamar a atenção de volta e tornar o espírito presente. (...) Daí que não raramente se ouça o 
homem comum rebentar uma sonora gargalhada nas partes mais comoventes de uma tragédia..." (p. 271-272). Não haveria uma espécie de aprendizado capaz de lidar com a imaginação? Uma racionalidade, ela mesma, estética? Capaz de avaliar, não a conformidade da obra a regras instrumentais, mas a regras, elas mesmas, estéticas, não redutíveis à linguagem conceitual? Isso desoneraria o excesso do namoro com o irracional, é claro.

Por tudo isso, o livro de Silke Kapp, Non Satis Est: excessos e teorias estéticas no Esclarecimento, é uma obra exemplar. Os objetivos teóricos claros, levados a cabo numa pesquisa textual competente, fazem da obra uma referência para os interessados em estética. $\mathrm{O}$ leitor em geral deve ser iniciado nas origens da discussão filosófica moderna sobre a arte, e o leitor especializado terá nas mãos uma argumentação "excessiva" em defesa de uma concepção especial da experiência estética. 